\title{
CARA PANDANG ETNIK SASAK YANG TERCERMIN DALAM NYANYIAN RAKYAT "KADAL NONGAQ"
}

\author{
ETHNIC PERSPECTIVE OF SASAK AS REFLECTED \\ IN “LIZARDS NONGAQ” FOLK SONG
}

\author{
Nining Nur Alaini \\ Kantor Bahasa Provinsi Nusa Tenggara Barat (NTB) \\ Jalan dr. Sujono, Kel. Jempong Baru, Kec. Sekarbela, Kota Mataram \\ niningkirono@yahoo.com
}

\begin{abstract}
Language and literature, as well as myth, painting, music, belief, and behavior are all simbols that have meanings. The symbolic forms have close links with the epistemological concepts of knowledge system of Sasak. Thus, the relationship between symbolic forms (literature or language) with a system of knowledge allows us to be able to know the knowledge of a particular system of reality or the perception of the world through their literature. Sasak system of knowledge of reality or the perception of the world can be revealed by examining the Sasak ethnic literature. This research revealed the system of Sasak knowledge of reality or perspective on the world and dismantled the cultural symbols that form the world view of the Sasak folk songs "Kadal Nongak". The signs examined were icons, indexes, and symbols in folk songs "Kadal Nongaq".
\end{abstract}

Keywords: perspective, literature, symbols.

\begin{abstract}
Abstrak
Bahasa dan sastra, sebagaimana mite, lukisan, musik, kepercayaan, dan tingkah laku merupakan symbol yang mengadung makna. Bentuk-bentuk simbolis tersebut mempunyai kaitan erat dengan konsep-konsep epistimologis dari sistem pengetahuan masyarakat Sasak. Dengan demikian, keeratan hubungan antara bentuk simbolis (sastra atau bahasa) dengan sistem pengetahuan masyarakat memungkinkan kita untuk dapat mengetahui sistem pengetahuan masyarakat Sasak terhadap realitas atau cara pandang tentang dunianya melalui sastra yang mereka miliki. Penelitian ini mengungkapkan sistem pengetahuan etnis Sasak terhadap realitas atau cara pandang tentang dunianya dan membongkar simbol-simbol budaya yang berupa pandangan dunia etnis Sasak yang terkandung dalam nyanyian rakyat "Kadal Nongak". Tanda-tanda yang dikaji adalah ikon, indeks, dan simbol dalam nyanyian rakyat "Kadal Nongaq".
\end{abstract}

Kata Kunci: cara pandang, sastra, simbol. 


\section{Latar Belakang Masalah}

Istilah folklor berasal dari kata folklore. Kata folklore berasal dari dua kata dasar folk dan lore. Folk berarti kolektif, yaitu sekelompok orang yang memiliki ciri-ciri pengenal fisik, sosial, dan kebudayaan, sehingga dapat dibedakan dari kelompok-kelompok lainnya. Folk bersinonim dengan kolektif yang juga memiliki ciri-ciri pengenal fisik atau kebudayaan yang sama, serta mempunyai kesadaran kepribadian sebagai kesatuan masyarakat, sedangkan lore adalah sebagian kebudayaannya, yang diwariskan secara turun-menurun secara lisan atau melalui suatu contoh yang disertai dengan gerak isyarat atau pembantu pengingat. Definisi folklor secara keseluruhan adalah kebudayaan suatu kolektif yang tersebar dan diwariskan turun temurun, di antara kolektif macam apa saja, secara tradisional dalam versi yang berbeda, baik dalam bentuk lisan maupun contoh yang disertai dengan gerak isyarat atau alat pembantu pengingat (Dananjaya, 1991: 1--2).

Bentuk-bentuk folklor, menurut Jan Harold Brunvand (via Dananjaya, 1991: 21), dapat dikategorikan menjadi folklor lisan, folklor sebagian lisan, dan folklor bukan lisan. Bentuk-bentuk folklor yang termasuk ke dalam kelompok besar ini antara lain a)bahasa rakyat seperti logat, julukan, pangkat tradisional, dan titel kebangswanan, b) ungkapan tradisional, seperti peribahasa, pepatah, dan pameo, c) pertanyaan tradisional, seperti teka-teki, d) puisi rakyat, seperti pantun, gurindam, dan syair, e) cerita prosa rakyat, seperti mite, legenda, dan dongeng, dan f) nyanyian rakyat (Danandjaya, 1991: 29--30).

Masyarakat lama adalah masyarakat yang komunal. Mereka memiliki persatuan yang lebih padu. Antara anggota masyarakat saling terikat satu sama lain. Setiap anggota masyarakat merasa dirinya merupakan bagian dari golongan. Sikap, perbuatan, pikiran, perasaan, kepercayaan, dan cita-citanya tidaklah berdiri sendiri, melainkan menyesuaikan diri dengan anggota masyarakatnya. Melihat kondisi masyarakat komunal yang demikian, diharapkan dengan mengkaji folklor lisannya yang merupakan bagian dari kebudayaan mereka, akan dapat diungkapkan sikap, perbuatan, pikiran, perasaan, kepercayaan, dan cita- cita mereka. Penelitian ini mencoba mengungkapkan pandangan hidup etnis Sasak di Pulau Lombok yang tercermin dalam folklor lisannya yang yang berwujud nyanyian rakyat berjudul "Kadal Nongak".

Menurut Peirce (Budiman, 2005: 95) sebuah karya sastra pada dasarnya tersusun atas tanda-tanda simbolis karena bahasa yang menjadimedia karya sastra selalu sudah merupakan sistem tanda-tanda konvensional. Melalui penelusuran dan analisis terhadap tanda-tanda simbolis tersebut akan terungkap pandangan hidup yang melatarbelakangi munculnya tanda-tanda simbolik tersebut, karena sebuah karya sastra tidak akan pernah terlepas daribudaya masyarakat yang melahirkan.

Dengan menganalisis folklor lisan etnis Sasak di Pulau Lombok yang berupa nyanyian rakyat berjudul "Kadal Nongak", diharapkan akan dapat diungkapkan pula cara pandang terhadap dunia etnis Sasak yang tercermin dalam folklor lisannya tersebut.

\section{Perumusan Masalah}

Penelitian ini akan mengungkapkan cara pandang etnis Sasak terhadap dunianya yang tercermin dalam nyanyian rakyat "Kadal Nongak".

\section{Tujuan Penelitian}

Sejalan dengan rumusan masalahnya, tujuan penelitian ini adalah mengungkapkan cara pandang etnis Sasak terhadap dunianya yang tercermin dalam nyanyian rakyat "Kadal Nongak".

\section{Kerangka Konseptual dan Landasan Teori}

\subsection{Kerangka Konseptual}

\subsubsection{Pandangan Dunia}

Pandangan dunia adalah seperangkat perasaan dan sikap dasar tentang dunia. Perasaan-perasaan dan sikap sebagian besar belajar di awal kehidupan dan tidak mudah berubah kemudian. Mereka memiliki pengaruh pada perilaku diamati tentu kita, baik verbal dan non-verbal. Pandangan dunia adalah orientasi kognitif mendasar suatu individu atau masyarakat yang mencakup seluruh pengetahuan dan sudut pan- 
dang individu atau masyarakat, anggapan fundamental, eksistensial, dan normatif, atau tema, nilai, emosi, dan etika. Selain itu, pandangan dunia ini juga mengacu pada kerangka kerja, ide dan kepercayaan suatu individu, kelompok, atau budaya dalam menafsirkan dunia dan berinteraksi dengannya (Wikipedia).

Pandangan dunia mendasari pengertian tentang wujud atau keterangan dan analisis tentang alam dalam setiap jalan dan filsafat hidup. Semua agama, adat-istiadat, aliran pemikiran dan filsafat sosial bertumpu dan berpijak pada satu pandangan dunia. Sebuah pandangan dunia yang baik dan luhur, memiliki karakter-karakter antara lain adalah sebagai berikut.

1. Dapat dideduksikan dan dibuktikan (didukung nalar dan logika), sehingga memudahkan jalan bagi diterimanya pandangan-dunia tersebut secara rasional, serta dapat dijadikan petunjuk dan menghilangkan kebingungan dan ketidaktahuan.

2. Mampu memberikan makna bagi kehidupan dan sanggup menghapuskan dari pikiran dan gagasan yang mengatakan bahwa hidup ini siasia, yang engarahkan perjalanan manusia pada ketidakberdayaan dan ketidakberartian.

3. Membangkitkan ideal-ideal, antusiasme, serta inspirasi sehingga memiliki daya-tarik, semangat dan kekuatan.

4. Sanggup memperkuat dan menyucikan maksud-maksud dan tujuan-tujuan sosial manusia, sehingga membuat orang mudah berkorban dan empertaruhkan diri demi maksud dan tujuan ini. Karena suatu mazhab pemikiran yg tidak dapat menyucikan tujuan-tujuannya dan tidak sanggup menanamkan rasa mengabdi berkorban dan idealisme, berkenaan dengan tujuan mazhab pemikiran tersebut, tentunya mazhab pemikiran tersebut tidak akan pernah memiliki jaminan, bahwa tujuan-tujuannya akan direalisasikan.

5. Membangkitkan komitmen dan rasa tanggungjawab, sehingga membuat orang bertanggungjawab atas dirinya dan masyarakatnya (Murtadha Muthahhari).

\subsubsection{Hubungan antara Karya Sastra dan Pandangan Dunia}

Bahasa dan kebudayaan, yang di dalamnya termasuk pandangan dunia, adalah dua disiplin ilmu yang berbeda. Akan tetapi bahasa dan budaya memiliki objek yang sama, yaitu manusia dalam masyarakat, manusia sebagai fakta sosial, manusia sebagai makhluk kultural (Ratna: 2005). Untuk melihat lebih lanjut bagaimana hubungan sastra dengan pandangan dunia, terlebih dahulu perlu dilihat bagaimana hubungan bahasa dengan kebudayaan, karena bahasa merupakan media utama yang digunakan oleh sastra. Terkait dengan hal ini, patut diperhatikan dua hipotesis dari Sapir dan Whorf tentang hubungan antara bahasa dengan pikiran. Dua hipoteis tersebut yaitu $l i-$ nguistik relativy hypotesis yang menyatakan bahwa perbedaan struktur bahasa secara umum paralel dengan perbedaan kognitifnon bahasa dan Linguistik determinism yang menyatakan bahwa struktur bahasa memengaruhi cara individu mempersepsikan dan menalar dunia (Sapir-Whorf dalam Widhiarso, 2004: 2). Dari dua hipotesis tersebut, terlihat bagaimana keeratan hubungan antara bahasa dengan pola pikir. Bahasa sangat memengaruhi bagaimana cara setiap individu mempersepsikan dan menalar dunianya. Sedangkan pola pikir dan cara menalar dunia tersebut tidak lain merupakan kebudayaan itu sendiri. Sebagaimana yang didefinisikan oleh Kontjaraningrat bahwa kebudayaan adalah seluruh sistem gagasan dan rasa, tindakan, serta karya yang dihasilkan manusia dalam kehidupan bermasyarakat, yang dijadikan miliknya dengan belajar.

Kuntowijoyo (2006) mengatakan bahwa bahasa dan sastra, sebagaimana mite, lukisan, musik, kepercayaan, dan tingkah laku merupakan simbol. Sebagai sebuah simbol, tentu semua itu memiliki kandungan makna. Lebih lanjut Kuntowojoyo mengatakan bahwa bentuk-bentuk simbolis tersebut mempunyai kaitan erat dengan konsep-konsep epistimologis dari sistem pengetahuan masyarakat. Dengan demikian, keeratan hubungan antara bentuk simbolis (sastra atau bahasa) dengan sistem pengetahuan masyarakat memungkinkan kita untuk dapat mengetahui sistem pengetahuan masyarakat tertentu terhadap realitas atau cara pandang terhadap dunianya melalui sastra 
yang mereka miliki. Sejiwa dengan apa yang dikatakan oleh Kuntowijoyo tersebut, Spradley (2007) juga mengatakan bahwa makna budaya diciptakan dengan menggunakan simbol-simbol. Lebih lanjut Spradley menjelaskan bahwa untuk mengetahui sistem makna budaya haruslah dilihat dari perspektif teori relasional tentang makna. Beberapa penegasan dasar teori relasional tentang makna tersebut yaitu: 1) sistem makna budaya disandikan dalam simbolsimbol, 2) bahasa merupakan sistem simbol utama yang menyandikan makna budaya dalam setiap masyarakat, 3) makna simbol apa pun merupakan hubungan dari simbol itu dengan simbol lain dalam budaya tertentu.

Dari apa yang telah dipaparkan di atas tentang bagaimana hubungan bahasa dengan pola pikir, bahasa dengan kebudayaan, dan sastra dengan kebudayaan, khususnya yang berkaitan dengan pandangan dunia, dapat dikatakan bahwa sistem pengetahuan itu tidak lain merupakan kebudayaan yang dapat diketahui dari bentuk-bentuk simbolis seperti bahasa, sastra, kepercayaan, dll. Jadi untuk dapat mengetahui kebudayaan tertentu dapat ditempuh melalui pemaknaan simbol-simbol yang digunakan oleh masyarakat penganut kebudayaan tersebut. Dengan demikian dari segi ini dapat dikatakan bahwa hubungan antara sastra dengan kebudayaan adalah sebagai pengungkap. Sastra dapat mengungkapkan nilai-nilai budaya, mempersepsikan dan menalar dunianya yang dianut oleh masyarakat pemiliknya karena nilai-nilai tersebut terkandung juga dalam sastra.

\subsubsection{Nyanyian Rakyat}

Nyanyian rakyat adalah salah satu bentuk folklor lisan yang terdiri dari kata-kata dan lagu, yang beredar secara lisan di antara kolektif tertentu, berbentuk tradisional, serta banyak mempunyai varian.

Dalam penggolongan Brunvand, nyanyian rakyat dikategorikan sebagai folklor lisan. Nyanyian rakyat dapat dibedakan dari nyayian lainnya, seperti nyanyian pop atau klasik, karena sifatnya yang khas, yaitu mudah berubah-ubah, baik bentuk maupun isinya. Sifat tidak kaku dari nyanyian rakyat ini tidak dimiliki oleh bentuk nyanyian lainnya. Hal ini disebabkan antara lain karena cara penyebaran nyanyian rakyat yang dilakukan secara lisan. Akan tetapi, di lain pihak umur nyanyian rakyat lebih panjang daripada bentuk nyanyian lain, karena nyanyian rakyat merupakan milik kolektif yang peredaran lebih luas dalam suatu komunitas. Untuk mengungkapkan pandangan dunia etnis Sasak, dalam penelitian ini akan dianalisis beberapa nyanyian rakyat yang populer dalam masyarakat Sasak, yaitu “Kadal Nongak". Populer di sini dalam arti, hampir semua komunitas Sasak yang ada di Pulau Lombok mengenal nyanyian tersebut.

Seperti yang telah diuraikan di atas, bahwa sifat nyanyian rakyat sangat fleksibel, mudah berubahubah, karena pengebaran yang dilakukan secara lisan. Maka, untuk menentukan data nyanyian rakyat yang akan dinalisis dalam kajian ini dilakukan perbandingan data nyanyian rakyat dengan judul yang sama, tetapi berbeda syairnya. Nyanyian rakyat yang syairnya paling banyak memiliki persamaan akan diambil sebagai data dengan pertimbangan nyanyian tersebut dianggap dapat mewakili secara luas etnis Sasak.

\section{Landasan Teori}

Makna sebuah karya sastra dibangun oleh tandatanda. Sistem yanda ini berhubungan dengan penanda (signifier) dan petanda (signified). Di dalam keduanya terdapat tiga tanda pokok, yaitu ikon, indeks, dan simbol. Ikon adalah hubungan antara penanda dan petanda yang bersifat alamiah berupa persamaan, misalnya sebuah foto merupakan penanda dari objek foto tersebut. Indeks merupakan hubungan antara penanda dan petanda yang bersifat alamiah berdasarkan hubungan sebab akibat. Salah satu contoh indeks ini adalah warna payung yang digunakan dalam upacara adat masyarakat Sasak menunjukkan identitas strata sosial penggunanya. Sedangkan simbol adalah hubungan antara penanda dan petanda yang tidak bersifat alamiah, tetapi bersifat arbitrer. Ada konvensi tertentu dari masyarakat pemilik pendukung simbol tersebut (Hawkes, 1978). Dalamkonvensi masyarakat Jawa, munculnya hewan tokek dikonotasikan dengan hal-hal yang bersifat negatif, misalnya tanda-tanda datangnya kekuatan jahat atau malapetaka, sementara itu, dalam masyarakat Sasak, sebaliknya, binatang tokek merupakan totem yang memiliki konotasi positif karena ia dianggap sebagai hewan yang mendatangkan keuntungan. 
Salah satu aspek yang penting dalam analisis simbol adalah hubungan antarteks. Terdapat dua pengertian tentang teks. Secara umum, teks diartikan sebagai dunia semesta yang menjadi latar belakang tercipnya teks. Artinya, dalam anggapan ini kondisi sosial budaya masyarakat merupakan sebuah teks. Secara khusus, teks adalah naskah itu sendiri, baik yang berwujud naskah tertulis, maupun lisan. Suatu teks tidak akan mempunyai arti penuh apabila tidak dihubungkan dengan teks latar (sosial budaya) karena teks latar merupakan bagian dari teks, dan sebaliknya teks merepresentasikan teks latar (Kristeva, 1980: 36-37). Oleh karena itu, untuk memahami makna nyanyian rakyat Sasak secara utuh, memerlukan pemahaman pula terhadap konteks sosial budaya masyarakat Sasak sebagai komunitas pemilik dan pendukungnya.

\section{Metode Penelitian}

\subsection{Data}

Data yang digunakan dalam penelitian ini adalah data primer dan data sekunder. Data primer yang digunakan adalah syair nyanyian rakyat Sasak yang berjudul "Kadal Nongak".

Secara utuh syair nyanyian rakyat 'kadal Nongaq' dapat disimak di bawah ini.

\section{Kadal Nongaq}

Kadal nongaq leq kesambiq

Benang kataq setakilan

Aduh dende

Mun cempake siq kembang sadat

Siq sengake jari sahabat

Tajah onyak ndeq me matiq

Payu salak kejariam

Aduh dende

Mun cempake siq kembang sadat

Siq sengake jari sahabat

Mun beguru impan sampi

Bau paoq leq kebon tengaq

Aduh dende

Mun cempake siq kembang sadat

Siq sengake jari sahabat

Mun beguru gati-gati

Adeq tao salaq kenaq

Aduh dende

Mun cempake siq kebang sadat

Saq sengake jari sahabat
Kadal mendongak ke pohon kesambiq

Benang mentah satu pintal

Aduh dende

Kalau cempaka bunga sandat

Yang lebih tua jadi sahabat

Diajarkan hati-hati tidak didengarkan

Akhirnya celaka

Aduh dinde

Kalau cempaka bunga sandat

Yang lebih tua jadi sahabat

Kalau belajar pelihara sapi

Petik mangga di kebun tengah

Aduh dende

Kalau cempaka bunga sandat

Yang lebih tua jadi sahabat

Kalau belajar giat-giat

Biar tahu salah dan benar

Aduh dende

Kalau cempaka bunga sandat

Yang lebih tua jadi sahabat 
Data sekunder merupakan data yang tidak berupa karya sastra, tetapi berkaitan erat dengan karya sastra. Data ini dapat berupa penelitian-penelitian tentang nyanyian rakyat "Kadal Nongak", kondisi sosial budaya masyarakat pemilik karya sastra, dan sebagainya.

\subsection{Teknik Pengumpulan Data}

Penelitian ini menggunakan dua macam data, yaitu data primer dan data sekunder.

Data primer adalah data yang berupa syair nyanyian rakyat "Kadal Nongaq". Data ini diperoleh dengan dua cara, yaitu dengan cara studi lapangan, artinya data diperoleh dari lokasi secara langsung, studi pustaka, dan studi katalog, yaitu dengan cara mengumpulkan data-data yang telah terdokumentasi, baik berbentuk rekaman maupun data-data pustaka.

Data sekunder merupakan data yang tidak berupa karya sastra, tetapi berkaitan erat dengan karya sastra. Data ini dapat berupa penelitian-penelitian tentang nyanyian rakyat "Kadal Nongaq", kondisi sosial budaya masyarakat pemilik karya sastra, dan sebagainya. Seperti halnya data primer, data sekunder juga dikumpulkan dengan dua cara, yaitu, melalui studi pustaka (library research), dan studi lapangan.

\subsection{Teknik Pengolahan Data}

Langkah-langkah pengolahan data yang dilakukan dalam penelitian ini adalah sebagai berikut.

1. Data rekaman ditranskripsikan atau dipindahkan dari bentuk rekaman ke bentuk tulisan. Kegiatan pentranskripsian dilakukan segera setelah perekaman data untuk memperkecil kemungkinan salah dengar.

2. Transkripsi yang berupa karya sastra dipisahkan dari transkripsi wawancara dengan informaninforman seperti audiens dan tokoh-tokoh yang lain.

3. Karya sastra yang telah ditranskripsi diterjemahkan dalam bahasa Indonesia untuk memudahkan pemahaman pembaca. Penterjemahan dilakukan secara terikat agar tidak mengubah struktur asli karya.

4. Transkripsi adalah pengubahan wicara menjadi bentuk tertulis, yaitu dengan cara menggam- barkan bunyi dengaan satu lambang. Transkripsi dalam sastra lisan berarti pemindahan bentuk lisan sastra lisan tersebut ke dalam tulisan. Proses transkripsi yang akan dilakukan dalam penelitian ini dilakukan dengan petranskripsian secara setia, dengan tujuan agar teks tidak berbeda jauh dari aslinya, namun demikian transkripsi yang dilakukan juga akan memasukkan unsur-unsur bahasa tulis, yaitu antara lain yang berkaitan dengan tanda baca dan huruf besar.

\section{Pembahasan}

\subsection{Nyanyian Rakyat "Kadal Nongaq"}

Nyanyian rakyat yang berjudul "Kadal Nongaq" ini sangat populer di kalangan etnis Sasak. Hampir semua anggota masyarakat Sasak di Pulau Lombok mengenal lagu ini, meskipun tidak semua menghafal syairnya.

Brunvand (via Danandjaya, 1991: 146) membedakan nyanyian rakyat menjadi nyanyian rakyat yang sesungguhnya dan nyanyian rakyat yang bukan sesungguhnya. Pengkategorian ini didasarkan pada peran syair dan lagu dalam nyanyian tersebut. Syair dan lagu dalam sebuah nyanyian rakyat merupakan dua hal yang tidak dapat dipisahkan. Dalam nyanyian rakyat yang sesungguhnya peran syair dan lagu setara, sedangkan dalam nyanyian rakyat yang bukan sesungguhnya hanya salah satunya yang memiliki peran yang dominan.

Nyanyian rakyat yang sesungguhnya dapat dibedakan menjadi 1) nyanyian rakyat yang berfungsi, 2) nyanyian rakyat yang bersifat liris, dan 3) nyanyian rakyat yang bersifat berkisah.

Nyanyian rakyat yang bersifat liris adalah nyanyian rakyat yang teksnya bersifat liris, yang merupakan pencetusan rasa dari pengarangnya yang anonim, tanpa menceritakan kisah yang bersambung. Sifat inilah yang membedakannya dari nyanyian liris yang bukan sesungguhnya, karena nyanyian liris yang bukan sesungguhnya justru menceritakan kisah yang bersambung.

Nyanyian liris yang sesungguhnya merupakan nyanyian yang liriknya mengungkapkan perasaan 
tanpa menceritakan suatu kisah yang bersambung. Nyanyian ini bisa berupa ungkapan perasaan sedih, putus asa, patah hati karena kehilangan cinta, anganangan dan nasihat, serta keinginan-keinginan yang tidak mungkin tercapai.

Nyanyian rakyat yang berjudul 'Kadal Nongaq' ini dari syairnya dapat dikategorikan sebagai nyanyian liris yang sesungguhnya karena lirik-liriknya bukan merupkan kisah yang bersambung. Nyanyian ini merupakan ungkapan perasaan penciptanya yang lebih mengarah kepada nasihat dan ajakan untuk menghormati dan menghargai yang lebih tua yang diungkapkan melalui ikon-ikon metaforis.

\subsection{Pandangan Dunia Etnis Sasak dalam Nyanyian Rakyat "Kadal Nongaq".}

Seperti yang telah dijelaskan di atas, karya sastra pada dasarnya tersusun atas tanda-tanda simbolik. Di balik simbolitasnya tersebut, karya sastra juga memanfaatkan dimensi-dimensi ketandaan yang lain, khususnya dimensi ikonis dan indeksikal.

Pengkategorian tanda-tanda menjadi indek, ikon, dan simbol merupakan pengkategorian yang didasarkan pada hubungan antara representamen dengan objeknya. Ikon adalah tanda yang didasarkan atas keserupaan atau kemiripan di antara representament dan objeknya. Ikon tidak semata-mata mencakup citra-citra realistis, seperti pada lukisan atau foto saja, melainkan juga ekspresi-ekspresi semacam grafik, skema, peta, bahkan metafora. Metafora merupakan suatu meta tanda yang ikonisitasnya berdasarkan pada kemiripan atau similaritas di antara objek-objek dari dua tanda simbolik. Indeks adalah tanda yang memiliki kaitan fisik, eksistensial, atau kausal di antara representamen dan objeknya sehingga seolah-olah akan kehilangan karakter yang menjadikannya tanda jika objeknya dipindahkan atau dihilangkan. Indeks juga terwujud dan teraktualisasi di dalam kata petunjuk, kata ganti persona, gerak gerik, seperti jari telunjuk dan menuding serta berbagai tanda visual lainnya. Demikian juga dengan "Kadal Nongak", syair-syair yang menyusun nyanyian ini merupakan susunan tanda-tanda simbolik.

Kekayaan ikonisitas yang terdapat dalam nyanyian rakyat 'Kadal Nongaq' ini akan ditelusuri dan dianalisis dengan membubuhi nomor urut untuk memudahkan penunjukkan, seperti yang terlihat pada tabel berikut.

\begin{tabular}{|c|l|l|}
\hline No. & \multicolumn{1}{|c|}{ Data } & \multicolumn{1}{|c|}{ Tipe } \\
\hline 1. & Kadal & Simbol \\
\hline 2. & Kesambiq & Simbol \\
\hline 3. & Kadal nongaq lek kesambiq & Simbol \\
\hline 4. & Benang kataq setakilan & Simbol \\
\hline 5. & Cempake & Simbol \\
\hline 6. & Kembang Sandat & Simbol \\
\hline 7. & Siq sengake jari sahabat & Ikon metaforis \\
\hline 8. & $\begin{array}{l}\text { Mun cempake siq kembang sandat } \\
\text { Siq sengake jari sahabat }\end{array}$ & Ikon diagramatis \\
\hline 9. & $\begin{array}{l}\text { Mun beguru... } \\
\text { Mun beguru... }\end{array}$ & Ikon diagramatis \\
\hline
\end{tabular}

Nyanyian rakyat 'Kadal Nongaq' ini cukup kaya dengan ikon dan simbol yang tersebar pada larik-larik syairnya. Simbolkadal yang berkorelasi dengan larik 'benang kataq setangkilan' berelasi dengan kemudaan, belum berpengalaman yang diper- lawankan dengan simbol 'kesambiq' yang berelasi dengan kedewasaan, kematangan, kemumpunian dalam pengetahuan dan pengalaman, mengayomi, membimbing, dan mengarahkan. Dalam larik 'kadal nongaq lek kesambiq' pembaca akan diarahkan kepada 
tanda yang mengacu kepada objek yang memiliki sifat yang mirip dengan kadal, yaitu sesuatu atau seseorang yang kecil dan lemah, nongaq (menegadah) merupakan gambaran sedang menimba pengalaman dan pengetahuan, sedangkan 'kesambiq' direlasikan dengan pohon kesambiq yang secara fisik merupakan pohon yang berkayu kokoh, berbatang tinggi dan besar, berdaun rimbun. Profil pohon kesambi yang rindang, kokoh, dan meneduhkan ini direlasikan dengan kedewasaan, kematangan, dan kemumpunian dalam pengetahuan dan pengalaman, sehingga mampu melindungi dan mengayomi, serta memberi keteduhan bagi lingkungan sekitarnya.

Simbol-simbol dan ikon-ikon yang terkandung dalam larik-larik nyanyian 'Kadal Nongaq' merupakan gambaran konsep nilai yang dipegang oleh etnis Sasask dalam hubungan antara sesamanya, yaitu bahwa seseorang harus menghargai yang lebih tua, yang merupakan leluhur dan cikal bakal keberadaan mereka di muka bumi ini. Makna kata 'tua' di sini tidak hanya terbatas pada ketuaan dari sisi usia saja, tetapi juga tua dalam makna strata sosial, kemampuan, ilmu pengetahuan, kedewasaan, dan sebagainya.

Dari segi kemasyarakatan, di kalangan masyarakat Sasak terdapat strata sosial yang membedakan kalangan bangsawan (permenak) dan rakyat biasa (jajar karang). Selain itu, di kalangan rakyat Sasak juga terdapat strata sosial yang dikaitkan dengan profesi, seperti Tuan Guru, Ustad, dan Kyai. Guru juga merupakan profesi yang cukup dihargai. Dampak dari adanya stratifikasi sosial tersebut adalah munculnya variasi-variasi panggilan dalam masyarakat (Windia, 2008: 85-86).

Status seseorang sebagai perwangsa (bangsawan) atau jajarkarang dapat diidentifikasi dari gelar yang disandangnya. Gelar mengawali nama diri dan digunakan dalam komunikasi sehari-hari. Gelar Rahadian atau Raden merupakan gelar bagi bangsawan pria dan biasanya disingkat dengan Den. Sedangkan wanita bangsawan menyandang gelar kehormatan Denda sebelum nama dirinya. Bangsawan yang sudah punya anak dipanggil Mamiq yang berarti ayah, sedangkan pria awam digelari amaq sebelum nama dirinya yang disingkat Maq, Gelar Lalu diberikan pada anak-anak bangsawan yang menikah dengan orang biasa, dan kaum wanitanya mendapat gelar Baiq. Dari tingkatan stratanya Lalu dan Baiq berkedudukan di bawah Raden dan Dende.

Wujud penghargaan etnis Sasak terhadap kaum bangsawan dapat dilihat dalam kehidupan bermasyarakat sehari-hari maupun dalam birokrasi pemerintahan. Hingga saat ini di beberapa tempat golongan bangsawan adalah elit yang memegang berbagai posisi penting, dalam lingkup tradisional dan birokratis. Dalam birokrasi pemerintahan, bangsawan menduduki jabatan pemerintahan di semua level, baik itu di kecamatan, maupun di dusun. Sejak zaman kolonial hingga awal masa kemerdekaan, bangsawan Bayan Timur menempati jabatan kepala Kecamatan Bayan, dan baru sesudah penghujung 1980-an jabatan ini diberikan pada orang lain dari Lombok Timur. Dari masa kolonial hingga sekarang yang menjadi kepala bagian Desa Bayan selalu berasal dari golongan bangsawan Bayan Timur (Budiwanti, 2000: 245246).

Dalam bidang kebudayaan dan agama, etnis Sasak mengenal istilah gelar Tuan Guru. Seorang Tuan Guru adalah tokoh yang terpandang dan dianggap memiliki kemampuan dan ilmu pengetahuan yang tinggi dalam bidang kebudayaan dan agama, sehingga ia bisa dijadikan sebagai panutan masyarakat sekitarnya. Kharisma Sang Tuan Guru diperoleh sesudah mereka menunaikan ibadah haji di Mekkah dan tinggal di sana selama dua tahun atau lebih untuk memperdalam agama Islam. Ikatan dan penghormatan etnis Sasak terhadap seorang Tuan Guru dimanisfestasikan dalam kunjungan berkala Tuan Guru untuk memberikan pengajian.

Etnis Sasak juga memegang nilai penghormatan kepada seseorang yang lebih tua dari segi usia. Hal ini dapat dilihat misalnya di tiga dusun besar Bayan Timur, Bayan Barat, dan Karangsalah, kedudukan bangsawan Bayan Timur dianggap lebih tinggi karena berdasarkan garis silsilah mereka lebih tua, sehingga status kebangsawanan mereka lebih tinggi. Dalam kehidupan sehari-hari penghargaan kepada yang berusia lebih tua juga diwujudkan dalam panggilan sehari-hari serta bahasa tubuh. Misalnya, jika melewati orang yang lebih tua mereka harus mengucapkan kata 'tabeq' (permisi) sebagai wujud penghormatan ter- 
hadap mereka. Juga tidak diperkenankan memanggil seseorang yang lebih tua dengan hanya menyebut namanya saja. Panggilan yang umum adalah $a m a q$ dan inaq.

Munculnya ikon diagramatis 'Mun cempaka siq kembang sandat, Siq sengake jari sahabat' dan 'Mun beguru....' pada larik-larik kedua sampai keempat dalam nyanyian 'Kadal Nongaq' tersebut merupakan penekanan terhadap penghargaan kepada yang lebih 'tua'. Mereka diibaratkan sebagai bunga cempaka dan bunga sandat yang indah dan semerbak wanginya. Indah karena berhiaskan dengan pengetahuan dan perilaku yang luhur, serta semerbak wanginya karena memberikan pengayoman, perlindungan, dan tuntunan kepada masyarakat sekitarnya, terutama kepada para muda yang masih minim pengalaman. Oleh karena itu, seseorang yang selalu menghargai dan meneladani apa yang diajarkan oleh para tetuanya akan selamat hidupnya di dunia dan akhirat, dan sebaliknya, mereka yang tidak mematuhinya akan mengalami penderitaan dan kesesatan karena salah langkah.

\section{Simpulan}

Setiap bahasa daerah biasanya akan diikuti dengan munculnya sastra daerah, dalam arti sastra yang media pengungkapannya adalah bahasa daerah. Etnis Sasak di Pulau Lombok memiliki bahasa daerah yang dipergunakan dalam komunikasi sehari-hari, yaitu bahasa Sasak. Selain sebagai sarana komunikasi, bahasa Sasak dalam etnis Sasak juga merupakan pengungkap media seni, yang salah satunya adalah seni sastra berupa folklor lisan. Etnis Sasak sangat kaya dengan tradisi folklor lisannya, antara lain berupa nyanyian rakyat "Kadal Nongak"

Nyanyian rakyat yang merupakan nyanyian nasihat ini mengandung nilai budaya yang dianut oleh etnis Sasak yaitu menghormati yang lebih tua. Konsep "tua" dalam etnis Sasak ini dapat mengacu pada tua dari segi usia, "tua" dalam hal ilmu pengetahuan dan pengalaman, "tua" dalam status sosial (bangsawan).

\section{Daftar Pustaka}

Danandjaja, James. 2002. Folklor Indonesia: Ilmu Gosip, Dongeng, dan Lain-lain. Jakarta: PT Grafiti Pers.

Endraswara, Suwardi. 2006. Metodologi Penelitian Kebudayaan. Yogyakarta: Gadjah Mada University Press.

Faruk, 2005. Pengantar Sosisologi Sastra: dari Strukturalisme Genetik sampai Pos-Modernisme. Yogyakarta: Pustaka Pelajar.

Faruk, 2005. Pengantar Sosisologi Sastra: dari Strukturalisme Genetik sampai Pos-Modernisme. Yogyakarta: Pustaka Pelajar.

Kuntowijoyo. 2006. Budaya dan Masyarakat. Yogyakarta : Tiara Wacana.

Muthahhari, Murtadha. Dalam www.goodreads. com > Religion > Islamý diakses 20 Februari 2014.

Saparie, Gunoto. 2007. Luasnya Wilayah Sosiologi Sastra dalam http://www.suarakarya-online. com/news.html?id=168818 diakses 18 November 2008

Tim Proyek Penelitian Bahasa dan Sastra Indonesia dan Daerah. 1986. Sastra Lisan Sasak. Jakarta : Pusat Pembinaan dan Pengembangan Bahasa.

Tim Redaksi. 2003. Kamus Besar Bahasa Indonesia. Jakarta: Balai Pustaka. 
